\title{
François-René de Chateaubriand, Viaggio in Italia
}

\section{Annalisa Bottacin}

\section{OpenEdition \\ Journals}

\section{Edizione digitale}

URL: http://journals.openedition.org/studifrancesi/5655

DOI: $10.4000 /$ studifrancesi.5655

ISSN: 2427-5856

\section{Editore}

Rosenberg \& Sellier

\section{Edizione cartacea}

Data di pubblicazione: 1 septembre 2011

Paginazione: 420-421

ISSN: 0039-2944

\section{Notizia bibliografica digitale}

Annalisa Bottacin, «François-René de Chateaubriand, Viaggio in Italia», Studi Francesi [Online], 164 (LV I II) | 2011, online dal 30 novembre 2015, consultato il 08 janvier 2021. URL: http://

journals.openedition.org/studifrancesi/5655; DOI: https://doi.org/10.4000/studifrancesi.5655

Questo documento è stato generato automaticamente il 8 janvier 2021.

\section{(c)}

Studi Francesi è distribuita con Licenza Creative Commons Attribuzione - Non commerciale - Non opere derivate 4.0 Internazionale. 


\title{
François-René de Chateaubriand, Viaggio in Italia
}

\author{
Annalisa Bottacin
}

\section{NOTIZIA}

FRANÇOIS-RENÉ DE CHATEAUBRIAND, Viaggio in Italia, a cura di Pierino GALLO, introduzione di Jean-Marie Roulin, Imola, Ed. La Mandragora, 2009, 121 pp.

1 Questa pregevole e accurata edizione, curata da Pierino Gallo, propone in traduzione italiana, corredata da un denso apparato di note (pp. 105-21), la corrispondenza e i frammenti diaristici che René de Chateaubriand indirizzò nel biennio 1803-1804 ai frequentatori del salon di Mme Pauline de Beaumont, con una particolare attenzione rivolta agli amici Joubert e Fontanes. Fu l'autore stesso nel 1827 a riunire queste pagine in un volume dal titolo Voyage en Italie.

2 Nel 1803-1804, Chateaubriand compì il suo primo viaggio nel Bel Paese, dei sei che effettuerà durante la sua esistenza. Un viaggio in cui «Roma e i paesaggi "classici", scoperti nel 1803, giungono a segnare una tappa fondamentale: la conoscenza dei testi greci e latini si accomuna al paesaggio, momento di confronto con la bellezza sensibile, soprattutto nel corso di passeggiate notturne che hanno ispirato gran parte dei romantici», come ben rileva nell'Introduzione Roulin (p.7). Delle città italiane che lo scrittore attraversa viene data una visione molto parziale; di Milano e Torino osserva la campagna e la regolarità urbanistica, la Toscana e Firenze sono descritte fugacemente, mentre Roma, la campagna romana, Napoli, il Vesuvio che scalerà, Pompei, Portici ed Ercolano sono narrate da un occhio critico e appassionato. È in particolar modo il paesaggio delle rovine a essere celebrato nel Voyage; paesaggi notturni dell'antica Roma e, tra le pagine più rappresentative, la Passeggiata notturna al chiaro di luna, in cui «[d]all'alto di Trinità dei Monti, i campanili e gli edifici lontano sembrano bozzetti sbiaditi di un pittore o coste disuguali viste dal mare, da una barca ancorata» (p. 59). 
3 Nel maggio del 1803, Chateaubriand fu nominato segretario di legazione a Roma al seguito del cardinal Fesch, ministro plenipotenziario presso la Santa Sede (questa la ragione dello spostamento in Italia), un incarico assai prestigioso che lo vide giungere nell'Urbe il 27 giugno 1803. Lascerà Roma il 27 giugno dell'anno seguente per una missione nel Valais. L'esecuzione del duca d'Enghien segnò comunque la fine dei rapporti tra Bonaparte e i legittimisti, cosicché Chateaubriand si lasciò alle spalle ogni nuovo incarico, passando all'opposizione.

4 La bella traduzione di Gallo evidenza ancora una volta la straordinaria importanza di questo testo nell'evoluzione della scrittura romantica, in particolar modo per le descrizioni paesaggistiche, dove le luci crepuscolari che avvolgono l'Urbe e le antiche rovine sono luogo ideale per meditare sulla caducità della vita e sulla morte. Il volume si compone inoltre di una cronologia, (pp.13-15) e di una serie di indicazioni bibliografiche (p. 123). 